\title{
The optimal number of offspring per gamete donor
}

\author{
Gunilla Sydsjö, Ulrik Kvist, Marie Bladh and Anders Nordgaard
}

\section{Linköping University Post Print}

\section{Tweet}

N.B.: When citing this work, cite the original article.

Original Publication:

Gunilla Sydsjö, Ulrik Kvist, Marie Bladh and Anders Nordgaard, The optimal number of offspring per gamete donor, 2015, Acta Obstetricia et Gynecologica Scandinavica, (94), 9, 1022-1026.

http://dx.doi.org/10.1111/aogs.12678

Copyright: Informa Healthcare / Wiley

http://eu.wiley.com/WileyCDA/

Postprint available at: Linköping University Electronic Press

http://urn.kb.se/resolve?urn=urn:nbn:se:liu:diva-120855 
The optimal number of offspring per gamete donor.

Gunilla Sydsjö ${ }^{1} \mathrm{PhD}$, Ulrik Kvist ${ }^{2} \mathrm{MD} \mathrm{PhD}$, Marie Bladh ${ }^{1} \mathrm{MA}$, Anders Nordgaard ${ }^{3} \mathrm{PhD}$

${ }^{1}$ Obstetrics and Gynaecology, Department of Clinical and Experimental Medicine, Faculty of Health Sciences, Linköping University, Linköping,

${ }^{2}$ Center for Andrology and Sexual Medicine, Karolinska University Hospital and Department of Medicine, Huddinge, Karolinska Institut, Stockholm,

${ }^{3}$ Swedish Police Authority - National Forensic Centre, Linköping and Department of Computer and Information Science, Linköping University, Linköping, Sweden

Correspondence:

Gunilla Sydsjö, Division of Obstetrics and Gynaecology, Department of Clinical and

Experimental Medicine, Faculty of Health Sciences, Linköping University, SE-581 85

Linköping, Sweden

tel: +46 13101038350 ; Email: Gunilla.Sydsjo@lio.se

Running title: Gamete donor limits 


\section{Conflict of interest}

The authors report no conflict of interest related to this manuscript. 


\begin{abstract}
Our aim was to create a mathematical basis to calculate the risks for unintended matings of consanguineous half-siblings from a donor in a society with approximately 10 million inhabitants. The Curie-Cohen model for calculation of the risk for consanguineous mating was used.

When the number of offspring per donor is limited to ten, then the model gives a yearly risk for consanguineous matings below $1 \%$. Thus 10 offspring gives a risk for consanguineous matings of $0.9 \%$ per year or approximately once in every 100 years. The risk increases exponentially: ith 15 offspring it exceeds $2 \%$ and with 25 it reaches up above $5 \%$.
\end{abstract}

Keywords: Number of children, donor, mathematical model, consanguinity, fertility 


\section{Introduction}

In 2002 and 2006 the Swedish National Board of Health and Welfare issued recommendations on assisted reproduction $(1,2)$ stating that "Eggs or sperm from a donor should not be used to result in the birth of more than six children by assisted reproduction." No documentation was available supporting this recommendation and when a new framework of guidelines was created to be in accordance with the EU-tissue directive, this recommendation was omitted (3). Following this, the seven clinics performing assisted reproduction with donated gametes were free to set the limits themselves. The Swedish national tissue group for gametes (VOG Könsceller) therefore temporarily advised that eggs and sperm from a single donor to be used to create children and siblings in six ART treated families.

In Sweden, the donor has no legal responsibilities towards the child, neither emotionally, financially or legally. Although gaining information about the identity of the recipients is not prohibited, the donors have no mandated legal right to know the identity of the couple receiving the donated gametes or of the child(ren) conceived by donated gametes.

However, in 1985 Sweden became the first country to pass a law stating that offspring resulting from donation have the legal right to receive identifying information about the donor when the child reach maturity $(2,4)$.

Subsequently, there has been considerable interest in other countries in what has happened in Sweden after the law had been implemented. Will the recipient couples inform their children, for example, and, if so, will the children take the opportunity to access information about their genetic origin and trace the donor and even contact the donor once the child has reached the age of maturity? Without doubt, this will have a special impact on the donor and possibly on other people close to the donor when that time comes. Thus, placing a limit on the number of offspring per donor will have ethical, psychological and medical consequences and an impact on the receiving couples, the man and the woman, women in a lesbian couple or single women, on the offspring, the siblings, and the donor and were the donor is identified, the donor's own children and family.

Recommendations on limits of offspring per gamete donor have in most countries been set arbitrarily, but there is now a movement to provide a rationale for setting a number. In the European Union (EU) countries the number of children per donor ranges between 5-25 offspring. The focus on sperm donors has been understandable since it has been rather easy to freeze and process millions of spermatozoa in bio-banks. Future technical developments in freezing oocytes might lead to a new debate on oocyte donors and their number of offspring, involving the same ethical and social dimensions as for the sperm donors, although the number of oocytes available from an individual donor is limited compared to the number of male gametes.

In order to have donors in the future who are motivated to donate and who will continue to have altruistic motives, it is necessary to establish and discuss an acceptable and safe limit of offspring per donor for all parties involved in the gamete donation process. One step to initiate this discussion is to calculate the risk for siblings having intercourse with siblings without knowing they were siblings and thereby cover the aspect of risk for consanguinity. 
Thus, the aim of this study was to adopt a mathematical model to find out how increasing numbers offspring per donor increases the risk in the Swedish society for unintended matings of consanguineous half-siblings from a donor.

\section{Method}

Several methods have been presented in the literature intended to provide a basis for setting sperm donor limits for infertility treatment to avoid consanguinity. Curie-Cohen presented a model in the 1980s that was based on considerations on consanguineous half-siblings from a donor mating and assuming that donors were anonymous (5). De Boer et al developed and used a model based on the Curie-Cohen model using a coefficient of inbreeding greater than $1 / 16$, assuming that the donor would be anonymous (6). Both methods used a mathematical model to link the risk of consanguineous mating to the number of offspring conceived using gametes from a single gamete donor. For this study we have used the model developed by Curie-Cohen since it was identified as the model that could most easily be implemented for Swedish data. For details regarding the implementation in Sweden, see Appendix A.

\section{Results}

The six studied regions in Sweden will be referred to as North (about 0.9 million individuals, Middle (about 1.9 million individuals), Stockholm (about 2 million individuals), West (about 1.7 million individuals), Southeast (about 1.0 million individuals), and South (about 1.7 million individuals) (Appendix A).

Figure 1 shows the relation between the expected number of consanguineous matings/year and the maximum number of offspring allowed per gamete donor, for different choices of the parameters involved in the calculation (Appendix A) The curve with dots represents the model with original settings, i.e. with values of parameters as initially observed estimated from Swedish data. To deem upon the sensitivity of the risk to these settings we have also altered the parameter values according to the discussion in Appendix A.

When the Swedish observations and estimates were put into the model we found a risk for consanguineous mating of $0.9 \%$ per year, corresponding to less than one consanguineous mating every 111 years, if each donor generated 10 children (Table 1 and Figure 1 ( dots)). With 25 offspring the risk for consanguineous mating increased to above $5 \%$ per year. To explore the reliability of these results we changed two of the major input variables (Appendix A), which resulted in minor variations and changes of $0.4-0.7$ percentage points in the risk for consanguineous mating when the number of offspring was 10 per donor. In this calculation the following applies:

1) d which is a combined expression relating how age differences affect couple formation and the observed age difference between half-siblings in Sweden (Southeast region). Increasing $\mathrm{d}$ to 0.02 increased the risk from 0.9 to $1.4 \%$ per year. i.e. from one in 111 years to one in 70 years.

2) $\mathrm{S}$ which is the number of gamete donors. Increasing the number of donors by $20 \%$ increased the risk for consanguineous mating by approximately 0.2 percentage points (Figure 1, open diamonds). Increasing both d to 0.02 as above and donors by $20 \%$ gave an increased risk for consanguineous mating reaching $1.7 \%$ per year (Figure 1, crosses). 
3) Q/A Q is an expression for the Swedish proportion of couples in a region where both come from the same region and $\mathrm{A}$ is the total number of births in the region.

Initially, in the original setting (Figure 1, dots) we used values of Q and A observed from the South-East region and applied these to the other regions by an up- or downscaling proportional to the size of each region, implying an increase in $\mathrm{Q}$ due to a larger region. However, the value of A was not affected by this scaling, which may be debated. In the curve with circles, we used the same Q/A originally calculated for the Southeast region for all regions resulting in a slightly lowered risk of approximately $0.5 \%$ for consanguineous matings.

\section{Discussion}

In this mathematical calculation of the optimal number of offspring/donor in a Swedish setting we found that if we limited the number of donor offspring to 10 , we have a risk for consanguineous matings of $0.9 \%$ per year or only once every 100 years. The rarity of such an event might be low enough to meet with general acceptance for the donor, the recipient couple, the children and for society in general. At this level of risk the sensitivity to the parameter settings is negligible. With 15 offspring the risk passes $2 \%$ and with 25 offspring it passes 5\%. The recommendation used earlier from the Swedish National Board of Health and Welfare which stated "Eggs or sperm from a donor should not be used to result in pregnancies leading to the birth of more than six children" can now be supported and verified by these new results and is still relevant and acceptable if the donors' present biological children as well as children to-be and siblings within the recipient couples are included (1-3).

There are arguments that no limit is needed since the risk for accidental half-sibling unions may become zero in all countries where the identity of the donors is open (7). The overall published understanding is not convincing since between 39-83\% of semen donor parents intend to, or actually do, tell their offspring that they were conceived by donated gametes (813). However, intending to inform ones offspring should be distinguished from actually telling them and one can suspect that the former leads to higher numbers than the latter (10). Lalos et al showed that $61 \%$ of parents in a Swedish cohort told their child about the donation, but less than two-thirds had not informed the child about the opportunity to have identification information about the donor (14). A known donation does not imply that the offspring will know his/her half-siblings in order to prevent consanguineous matings.

In a large semen bank in the Netherlands, with a system providing an option between anonymous and identifiable donorship, a quite significant proportion of parents (37\%) opted for anonymous donors and the reasons for that was commonly because of worries that traceable donors might interfere with their family life (11).

The predicament that some individuals will have to face in having as many as 50 halfsiblings, which could occur where there is no limitation on the number of offspring per donor, might involve future ethical, medical and psychological issues. Clinics recruiting donors without looking carefully into the medical and psychological history of the donor may be setting the stage for creating a serious dilemma for society and future patients regarding levels of trust in the providers of these kinds of treatments.

One can debate how much knowledge a young person around 20 years of age has about inherited family diseases or genetic diseases with late onset, since the young person's parents and siblings may be too young to have yet developed such disease states. For the donor there 
are different aspects concerning the plausible and acceptable number of offspring. In a recent follow-up study the majority of both sperm and oocyte donors who all had donated 5-8 years ago consider 1-10 offspring acceptable (15).

Although the EU demands only altruistic donation, there could be individual economic reasons to donate numerous times. However, the most commonly stated ground among gamete donors is "to help others". For donors exposed in the media as carriers of a disease that has a high probability to be heritable, the psychological and moral ethical dilemmas might become a major problem and even a personal tragedy. Recently a group of European authors aimed at a holistic approach on the maximal offspring number per donor, considering perspectives of genetics, psychosocial, ethics, donor availability, and legal issues (16).

Swedish gamete donors are all traceable and records are kept at university clinics, since treatments with donated eggs and sperm can only be done there. These donors have recently been evaluated with regard to demographic and personality traits, and the mean sperm donor's age was $33.8 \pm 7.8$ years and one-third of the donors had biological children of their own. They perceived themselves as autonomous with a capacity to take responsibility, to behave in a goal directed manner, to be resourceful and self-acceptant and to behave in a manner guided by meaningful values and goals (17). For egg donors the mean age was $30.3 \pm 4.5$ years and the majority $(65 \%)$ had biological children of their own. Egg donors considered themselves to have a mature and stable character (18). For the majority of donors, the reasons for donating were altruistic (95\%). A greater percentage of egg than sperm donors had a personal experience of biological children, which motivated them to donate (65 vs. 32\%). The men donating sperm also believed that they were contributing what they regarded as their own good genes to other couples (45\%), whereas $20 \%$ of the egg donors felt they were contributing "good" genes (19).

From a human perspective people should be free to choose the way they will pursue their reproductive interests, when to perform it and with whom. The risk for consanguineous matings would be lowest if gametes were distributed worldwide in a random fashion, but clinics order gametes from their distributors and serve people mostly living in a restricted geographical area like the Swedish six regions with 1-2 million habitants. Thus, the results from this study would hold also for international actors.

For a society with a population of 10 million inhabitants and with widely held Swedish attitudes concerning reproduction, donor recruitment and mobility within the country, a limit of 10 offspring/donor gives a risk for consanguineous matings of $0.9 \%$ per year or once every 100 years. The risk value of $0.9 \%$ appears low enough to meet general acceptance, i.e. for the donor, the recipient couple or individuals, for the children and the donor to be, as well as for society in general.

\section{Acknowledgments}

Financial support was given by the National Tissue Group for Gametes (VOG Könsceller) at the National Council for Human Organs and Tissues (Nationella Vävnadsrådet) at the Swedish Association of Local Authorities and Regions (SALAR). 


\section{References}

1. Swedish National Board of Health and Welfare:SOSFS 2002:13.

2. Swedish National Board of Health and Welfare:SOSFS 2006:10.

3. Swedish National Board of Health and Welfare:SOSFS 2009:32.

4. Ministry of Health and social affairs SFS1983:1140.

5. Curie-Cohen M. The frequency of consanguineous matings due to multiple use of donors in artificial insemination. Am J Hum Genet. 1980 Jul;32(4):589-600.

6. de Boer A, Oosterwijk JC, Rigters-Aris CA. Determination of a maximum number of artificial inseminations by donor children per sperm donor. Fertil Steril. 1995 Feb;63(2):419-21.

7. Sawyer N. Sperm donor limits that control for the 'relative' risk associated with the use of open-identity donors. Hum Reprod. 2010;25(5):1089-96. Epub 2010 Feb 19.

8. Gottlieb C, Lalos O, Lindblad F. Disclosure of donor inseminations to child: the impact of Swedish legislation on couples' attitudes. Hum Reprod. 2000; 15:2052-6.

9. Scheib JE, Riordan M, Rubin S. Choosing identity-release sperm donors: the parents' perspective 13-18 years later. Hum Reprod. 2003;18(5):1115-27.

10 Golombok S, Jadva V, Lycett E, Murry C. Families created by gamete donation : a followup at age 2. Hum Reprod. 2005;20:286-93. Epub 2004 Nov 11.

11. Brewaeys A, de Bruyn JK, Louwe LA, Helmerhorst FM. Anonymous or identityregistered sperm donors? A study of Dutch recipients' choices. Hum Reprod. 2005;20:820_4. Epub 2005 Jan 27.

12. Lycette E, Daniels K, Curson R, Golombok S. Offspring created as a result of donor insemination: a study of family relationship, child adjustment, and disclosure. Fertil Steril. 2004;82:172-9.

13. Isaksson S, Skoog Svanberg A, Sydsjö G, Thurin-Kjellberg A, Karlström PO, Solensten NG et alTwo decades after legislation on identifiable donors in Sweden are recipient couples ready to be open about using gamete donation? Hum Reprod. 2011; 26(4): 853-860.

14. Lalos A, Gottlieb C, Lalos O. Legislated right for donor-insemination children to know their genetic origin: a study of parental thinking. Hum Reprod. 2007 ;22(6):1759-68.

15. Sydsjö G, Lampic C, Bladh M, Skoog Svanberg A. Oocyte and sperm donors'opinions on the acceptable number of offspring. Acta Obstet Gynecol Scand. 2014;93(7):634-9. Epub 2014 May 12

16. Pim M.W. Janssens, Petra Thorn, Jose A. Castilla, Lucy Frith, Marilyn Crawshaw, Monique Mochtar, Lars Bjorndahl, Ulrik Kvist, JacksonC. Kirkman-Brown, Evolving minimum standards in responsible international sperm donor offspring quota, in press Reproductive BioMedicine Online (2015), doi: 10.1016/j.rbmo.2015.01.018

17. Sydsjö G, Lampic C, Brändström S, Gudmundsson J, Karlström PO, Solensten NG et al Who becomes a sperm donor: personality characteristics in a national sample of identifiable donors. BJOG. 2012;119(1):33-9. Epub 2011 Oct 18.

18. Sydsjö G, Lampic C, Brändström S, Gudmundsson J, Karlström PO, Solensten NG et al Personality characteristics in a Swedish national sample of identifiable oocyte donors. BJOG. 2011;118(9):1067-72. Epub 2011 Apr 11.

19. Skoog Svanberg A, Lampic C, Gudmundsson J, Karlström PO, Solensten NG, Geijerwall A-L et al. Gamete donors' motivation in a Swedish national sample: Is there 
any ambivalence? A descriptive study. Acta Obstet Gynecol Scand. 2012; 91(8):944951. 


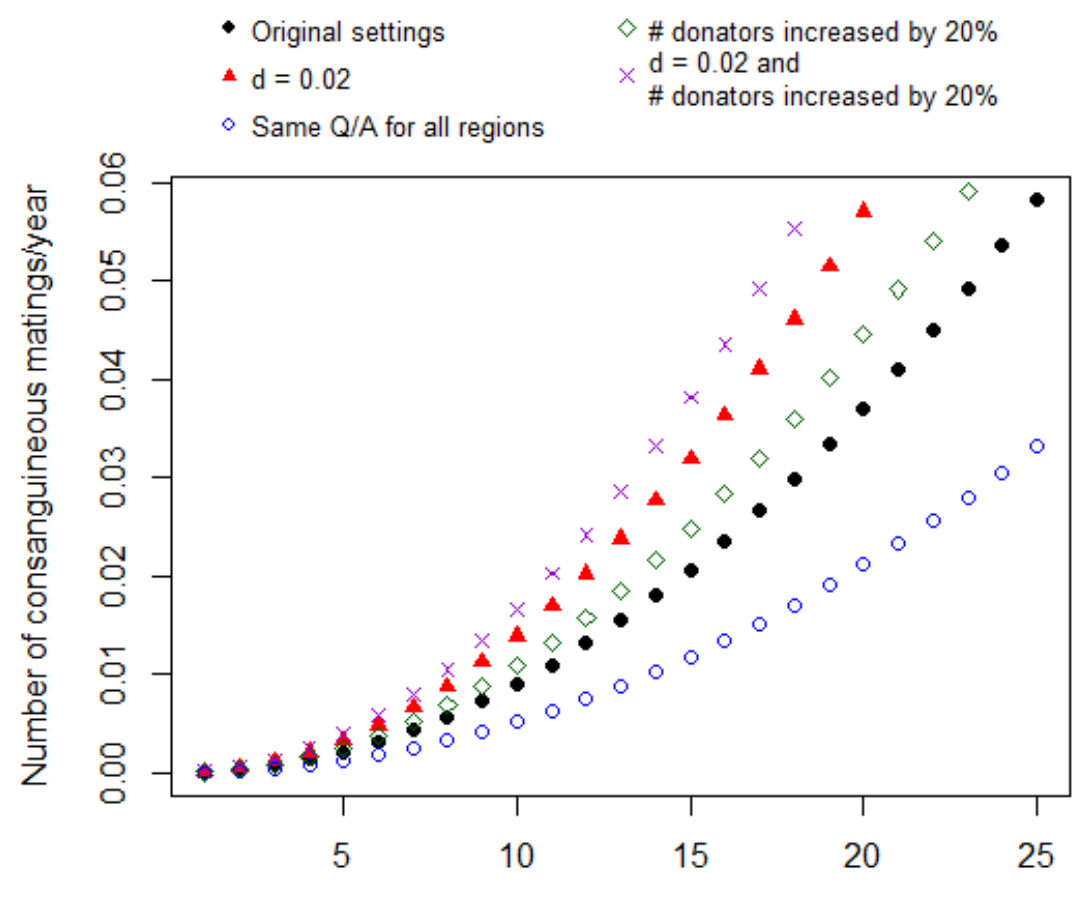

Number of offspring per gamete donator

Figure 1: Expected number of consanguineous matings per year as a function of the maximum number of offspring per gamete donor. 
Table 1. Risk for consanguineous mating expressed in percent and number of occurrences per year.

\begin{tabular}{c|c|c|c}
\hline $\begin{array}{c}\text { No. of offspring } \\
\text { per donor }\end{array}$ & Risk & Risk in \%/year & $\begin{array}{c}\text { Occurrence in } \\
\text { no. years }\end{array}$ \\
\hline 3 & 0.0007 & 0.07 & $1 / 1429$ \\
5 & 0.0021 & 0.21 & $1 / 476$ \\
10 & 0.0090 & 0.90 & $1 / 111$ \\
25 & 0.0583 & 5.83 & $1 / 17$ \\
\hline
\end{tabular}


